\title{
LEAF GAS EXCHANGE AND COMPETITIVE ABILITY OF Zea mays AND Sorghum halepense AS AFFECTED BY WATER COMPETITION
}

\author{
H. ACCIARESI ${ }^{1,2}$, M. YANNICCARI $^{2}$, E. LEGUIZAMÓN $^{3}$ and J. GUIAMET ${ }^{2}$ \\ ${ }^{1}$ CEREALICULTURA, FACULTAD DE CIENCIAS AGRARIAS Y FORESTALES, UNIVERSIDAD \\ NACIONAL DE LA PLATA, ARGENTINA; ${ }^{2}$ INSTITUTO DE FISIOLOGÍA VEGETAL (UNLP- \\ CONICET), LA PLATA, ARGENTINA; ${ }^{3}$ DEPARTMENT OF CROP PRODUCTION SYSTEMS-WEEDS, \\ FACULTAD DE CIENCIAS AGRARIAS, UNIVERSIDAD NACIONAL DE ROSARIO, ZAVALLA, \\ ARGENTINA
}

Received: 16 February, 2012; accepted: 10 April, 2012

\begin{abstract}
In an environment involving water deficit and competition, weed species may show inefficient water use. The aim was to determine the water consumption strategy of Zea mays and Sorghum halepense and the effects of these strategies on crop and weed competitive ability.

Under two soil water availability conditions, the soil and leaf water potential $\left(\Psi_{1}\right)$, relative water content (RWC) and leaf gas exchange parameters were measured during the critical period of crop competition in pot experiments where $Z$. mays and S. halepense were grown alone or in competition. In addition, the relative yield total and aggressivity index of both species were calculated.

$S$. halepense showed continuous absorption of water, reaching a lower $\Psi_{1}$ than the $Z$. mays hybrids. $S$. halepense maintained a RWC of above $90 \%$, which only decreased to $70 \%$ in the case of competition for low water supplies. In Z. mays, RWC declined to values of $70 \%$ at both water levels. $S$. halepense exhibited active leaf gas exchange. $Z$. mays hybrids had lower competitive ability than $S$. halepense at both competition levels due to their conservative water use strategy. Sustained water use by the weed could be the cause of the increased aggressivity of $S$. halepense under water deficit conditions.
\end{abstract}

Key words: water potential, relative water content, relative yield total, aggressivity, Johnsongrass, instantaneous water use efficiency

\section{Introduction}

Water is one of the main resources limiting the productivity of agroecosystems (Bohnert and Bressan, 2001). Plant species differ widely in their responses to soil water conditions, and these responses affect the competitive ability of weeds (Acciaresi and Guiamet, 2010; Leguizamón et al., 2011). The result of competition between crop and weeds is related to the relative ability of both components to capture the limiting resource and to tolerate low levels of this resource. Crop-weed water competition has been defined as an increase in water stress caused reciprocally by each component of the association (Radosevich et al., 1997). 
Different crop and weed traits have been linked to greater tolerance to water deficit. The presence of a dense root system (Caldwell et al., 1996), the maintenance of root elongation at low soil water levels (Bates and Lynch, 2001), the ability to keep stomata open at low leaf water potentials (Tsuji et al., 2003), possibly through osmotic adjustment (Hsiao and $\mathrm{Xu}, 2000$ ), and the ability to decrease growth rate and reproduction (Ray et al., 1997; Ray and Sinclair, 1997) have been identified as valuable traits under drought conditions.

Several studies have established that, within the range of leaf relative water contents (RWC) experienced in different agroecosystems under slowly declining soil moisture contents (as usually occurs in agricultural systems; Chaves et al., 2002), stomatal closure leads to reduced availability of $\mathrm{CO}_{2}$, leading to a decrease in the photosynthesis rate (Chaves et al., 2002; Cornic and Fresneau, 2002). However, many weed species do not use water efficiently under water competition, appearing as "water wasters" (Patterson, 1995), because the stomata of many weed species are less sensitive to declining leaf water potential than those of the crops with which they compete (Geddes et al., 1979). Stuart et al. (1985) established that under water deficit conditions Sorghum halepense tends to make less efficient use of water, resulting in more vigorous competition for soil water.

In sub-humid regions one appropriate crop breeding strategy is water conservation through reduced stomatal conductance, a feature that leads to more stable crop production (Turner, 2001). However, this strategy of high water use efficiency may give a competitive advantage to "water waster" weeds, which may therefore maintain higher growth rates during the competition period (Patterson, 1995). Thus, the determination of the strategies of different species in response to water deficit will establish the impact that competition will have on crop and weed productivity (Semere and Froud-Williams, 2001).

Weed and crop competition for water has been reviewed extensively (Patterson, 1995), but knowledge about the competition for water between Zea mays and its weeds is limited. Often, studies on crop-weed competition for water have considered only one parameter (i.e. leaf water potential) measured only once during the growing period (Rajcan and Swanton, 2001). These authors stated that to understand the principles of competition for water the competitive process should be viewed as an outcome of the interactions between two dynamic systems: the soil-plant-atmosphere system and the crop-weed system.

The objectives of this study were to establish the dynamics of leaf gas exchange in Zea mays and Sorghum halepense during competition for water, and to determine the water consumption strategy of each species and the effects of these strategies on crop and weed competitive ability.

The hypotheses underlying this work were that:

- Sorghum halepense maintains a higher leaf gas exchange rate than Zea mays during competition for water, a strategy that allows Sorghum to absorb water at the expense of Zea mays. 
- Increased gas exchange and water consumption give Sorghum halepense greater competitive ability compared to Zea mays during the critical period of competition.

\section{Materials and methods}

The experiments were carried out outdoors at the Instituto de Fisiología Vegetal (Facultad de Ciencias Agrarias y Forestales, Universidad Nacional de La Plata, $34^{\circ} \mathrm{S}, 58^{\circ} \mathrm{W}$, Argentina) during the growing period October-January in 2003-2004 and 2005-2006.

Plant material and growth conditions

Rhizomes of Sorghum halepense were collected from natural populations in La Plata. The rhizomes were cut into pieces with two nodes each, weighing from 4 to $7 \mathrm{~g}$. The rhizome pieces were washed free of soil and soaked in a solution of $0.35 \mathrm{~g} \mathrm{l}^{-1}$ benomyl for 15 minutes. Two maize hybrids (Ax888 and Ax840), having an intermediate cycle with 118 and 119 days to physiological maturity, were used. Thirty $\mathrm{dm}^{3}$ pots were filled with a clay-loam soil, peat moss and sand mixture $(0.4: 0.25: 0.35 \mathrm{v} / \mathrm{v})$, and each pot was fertilized with $500 \mathrm{mg}$ of $\mathrm{N}$ applied as urea and $620 \mathrm{mg}$ of $\mathrm{P}_{2} \mathrm{O}_{5}$ applied as calcium triple superphosphate at planting to prevent nitrogen and phosphorus deficiencies. The final composition of the soil substrate was $3.05 \%$ organic matter, $2.15 \%$ organic carbon, $0.26 \%$ total nitrogen, $32.8 \mathrm{ppm}$ nitrate and $14.2 \mathrm{ppm}$ available phosphorus (Bray Kurtz II), with a $\mathrm{pH}$ of 6.7. The water retention values of the substrate were: $0.45 \mathrm{~cm}^{3} \mathrm{~cm}^{-3}$ of water at a soil water potential of $-0.001 \mathrm{MPa}, 0.25 \mathrm{~cm}^{3} \mathrm{~cm}^{-3}$ at $-0.02 \mathrm{MPa}$ and $0.20 \mathrm{~cm}^{3} \mathrm{~cm}^{-3}$ at $-0.2 \mathrm{MPa}$.

Each pot contained a single plant pot $^{-1}$ in the monoculture treatment and one plant pot ${ }^{-1}$ each of $S$. halepense and Z. mays in the competition treatment. The pots were watered every day in order to maintain the soil water content at $-0.03 \mathrm{MPa}$, approximately field capacity (FC), up to 21 days after emergence, when treatments involving low water availability ( $\mathrm{L}, 75 \%$ of field capacity, $-0.04 \mathrm{MPa}, 23.5-25 \%$ moisture, $\mathrm{w} / \mathrm{w}$ ) and very low water availability (VL, irrigation withheld) were established. The experiment lasted 24 days (until 45 days after emergence), which corresponded to the critical period of weed competition for maize (V4-V7) (4-7 leaves expanded) (Ghosheh et al., 1996). Monocultures of Sorghum halepense and Zea mays were used as control treatments. The control pots were watered daily in order to maintain the soil water content near $-0.03 \mathrm{MPa}(\mathrm{FC})$, determined by means of a water potential probe (Thermolink soil multimeter; Decagon Devices, Pullman, USA). The soil surface in pots in the very low water availability treatment was covered with polystyrene beads to minimise soil evaporation.

For dry mass determination, the plants were cut off at ground level and the above-ground plant parts were oven dried at $48^{\circ} \mathrm{C}$ (constant weight). The aboveground dry matter data were used to calculate aggressivity (AGR) and relative yield total (RYT).

A randomized complete block additive design with five replicates was used, where each container was an experimental unit.

\section{Measurements and variables}

Soil water potential $\left(\psi_{\mathrm{s}}, \mathrm{MPa}\right)$ was determined every three days during the experimental period using a porous capsule (Thermolink, Decagon Devices, Pullman, USA) buried in the pot at $20 \mathrm{~cm}$ depth.

Leaf water potential $\left(\psi_{1}, \mathrm{MPa}\right)$ was determined on a leaf disc (approximately $1 \mathrm{~cm}$ in diameter) excised from the penultimate expanded leaf using psychometric thermocouples (C-52, Wescor, UT, USA) connected to a microvoltimeter (HR-33T, Wescor, UT, USA). Leaf discs were taken and measured at about 8:00 am (one sample per plant was taken from each experimental unit).

Relative water content (RWC, \%) was estimated every three days from 12:00 to 14:00 pm according to Jones and Turner (1978). A leaf section (approximately $3 \mathrm{~cm} \times 1 \mathrm{~cm}$, excluding the midvein) was taken from the central third of the last expanded leaf. The samples were placed in 
flasks provided with air-tight screw-caps. The flasks were placed in polystyrene containers filled with ice at the bottom to maintain a constant temperature of $12-15^{\circ} \mathrm{C}$ until the end of the sampling period. In the laboratory, the samples were weighed fresh (W) and placed in petri dishes containing distilled water for $4 \mathrm{~h}$ at room temperature. Then the excess water was drained from the samples, which were blotted using filter paper and weighed to determine turgid weight (TW). The samples were then oven dried at $80^{\circ} \mathrm{C}$ for $24 \mathrm{~h}$ and weighed to determine dry weight (DW). RWC was calculated as follows:

$$
\mathrm{RWC}(\%)=[(\mathrm{W}-\mathrm{DW}) /(\mathrm{TW}-\mathrm{DW})] \times 100
$$

where: W (fresh weight, mg), TW (turgid weight, mg) and DW (dry weight, mg). One sample per plant was taken in each experimental unit.

The photosynthetic rate $\left(\mathrm{A}, \mu \mathrm{mol} \mathrm{CO} \mathrm{Cm}^{-2} \mathrm{~s}^{-1}\right)$ was measured between 10:00 and 13:00 pm on the last expanded leaf of both species. A portable infrared gas analyser was used (IRGA, LI6200 , LI-COR, NE, USA). The leaves were placed in a $1 \mathrm{dm}^{3}$-volume chamber and measurements (one per plant from each experimental unit) were conducted in a closed configuration at ambient irradiance and temperature. Since the determinations were performed on sunny days no additional photosynthetically active radiation was provided.

The stomatal conductance to water vapour $\left(\mathrm{G}_{\mathrm{s}}\right)$ and the transpiration rate $(\mathrm{E})\left(\mathrm{mmol} \mathrm{H}_{2} \mathrm{O}\right.$ $\mathrm{m}^{-2} \mathrm{~s}^{-1}$ ) were measured on the abaxial side of the last expanded leaf exposed to solar radiation. Measurements were made using a porometer (LI-1600, LI-COR, NE, USA) under the same conditions as described for the photosynthetic rate. The instantaneous water use efficiency (IWUE, $\mu \mathrm{mol} \mathrm{CO} \mathrm{Cmol} \mathrm{H}_{2} \mathrm{O}^{-1}$ ) was calculated using the values obtained for A and E (Dudley, 1996).

Resource complementarity and competitive ability

The relative yield total (RYT) (de Witt and Van der Bergh, 1965) and the competitive ability (aggressivity index, AGR) (Satorre and Snaydon, 1992) were calculated as follows:

$$
\begin{gathered}
\mathrm{RYT}=\left(\mathrm{Y}_{\mathrm{ij}} / \mathrm{Y}_{\mathrm{ii}}\right)+\left(\mathrm{Y}_{\mathrm{ji}} / \mathrm{Y}_{\mathrm{jj}}\right) \\
\operatorname{AGR}=\left[\left(\mathrm{Y}_{\mathrm{ij}} / \mathrm{Y}_{\mathrm{ii}}\right)-\left(\mathrm{Y}_{\mathrm{ji}} / \mathrm{Y}_{\mathrm{jj}}\right)\right] \times \mathrm{RYT}^{-1}
\end{gathered}
$$

where $\mathrm{Y}_{\mathrm{ij}}$ and $\mathrm{Y}_{\mathrm{ji}}$ are the above-ground biomass per plant of species ${ }_{\mathrm{i}}$ (maize) and ${ }_{\mathrm{j}}$ (S. halepense) when grown together, and $Y_{i i}$ and $Y_{j j}$ are their above-ground biomass when grown in a monoculture.

\section{Statistical analysis}

Differences between genotypes, water availability and competition were tested by combined analysis of variance on the ln-transformed variables (Poorter and Lewis, 1986; Kalapos et al., 1996). A significant interaction between treatments and time indicates a difference in the variable analysed (Poorter and Lewis, 1986; Kalapos et al., 1996; Sultan et al., 1998). Standard error (SE) was used to analyse treatment effects. Analyses of variance were also performed on the RYT and AGR values. Residual plots indicated that the variance of these variables was normally distributed and homogeneous. The statistical package Statgraphics plus 5.1 was used to perform the analyses.

\section{Results}

The treatment by year interactions showed no significant differences $(\mathrm{p}=0.48)$, so the data across years were combined to show the two-year averages.

\section{Soil $\left(\psi_{s}\right)$ and leaf water potential $\left(\psi_{l}\right)$}

Throughout the experimental period, there were no differences in the $\psi_{\mathrm{s}}$ values of watered monocultures. The $\psi_{\mathrm{s}}$ values observed in the monoculture 
under very low water availability $(\mathrm{VL})$ were significantly lower $(\mathrm{p}<0.05)$ than those for the watered monocultures nine days from the start of the water availability treatments (Fig. 1). The low water availability treatment (L) also caused a significant decrease $(\mathrm{p}<0.05)$ in the $\psi_{\mathrm{s}}$ of the monocultures, this reduction being greater in Sorghum halepense than in either of the Zea mays hybrids. The $\psi_{\mathrm{s}}$ values decreased significantly as early as four days after the start of the testing period (24 DAE) in the competitive VL treatment $(p<0.01)$ compared with the relevant $\mathrm{L}$ treatment.

In the $\mathrm{L}$ treatment, a significant decrease $(\mathrm{p}<0.05)$ was observed in the $\psi_{1}$ of the Sorghum halepense mixture fifteen days from the beginning of the experimental period (Fig. 2a). The effect of a low water level on the $\psi_{1}$ of Sorghum halepense was similar in monoculture and in competition with both Zea mays hybrids. At the end of the testing period, the average value of $\psi_{1}$ for Sorghum halepense, in competition with either hybrid, was $-1.44 \mathrm{Mpa}$, which was not significantly different from that reached in monoculture $(-1.68 \mathrm{MPa})$. In competititon with maize, the VL treatment produced a significant reduction $(p<0.05)$ in the $\psi_{1}$ of Sorghum halepense compared to the well-watered control, starting from the tenth day after the beginning of the testing period. Under VL, Sorghum halepense plants reached a final $\psi_{1}$ value of $-2.55 \mathrm{MPa}$ (averaged over the maize hybrids).

For both Zea mays hybrids, reduced water availability and weed competition produced a significant decrease in $\psi_{1}$ as early as five days after the beginning of the water availability treatments (Fig. 2b). $\psi_{1}$ decreased until 31 DAE, but thereafter remained constant with no significant fluctuations in any of the treatments tested.

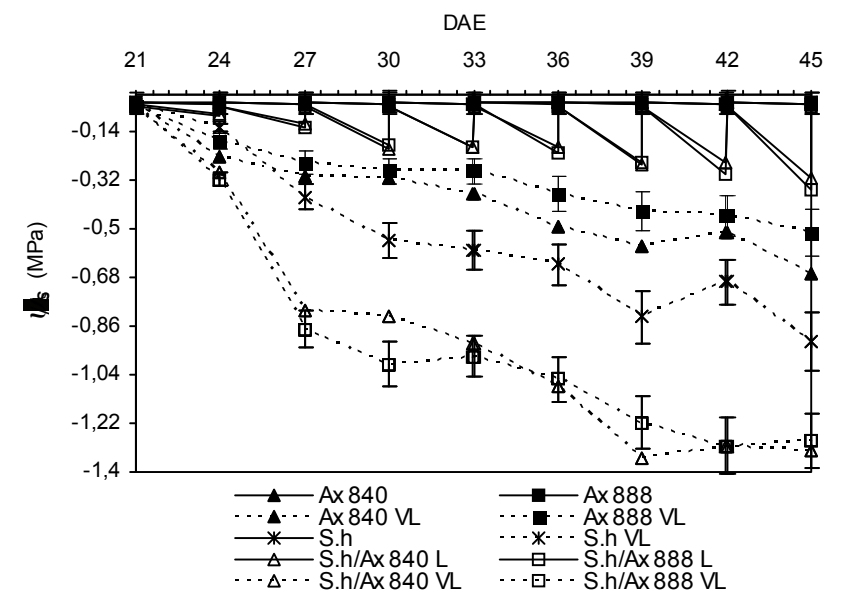

Fig. 1. Time-course of soil water potential ( $\left.\psi_{\mathrm{s}}, \mathrm{MPa}\right)$ for Zea mays (Ax 840 and Ax 888) and Sorghum halepense (S.h) monocultures grown at field capacity and with very low (VL) water availability and for Sorghum halepense in competition with Zea mays (S.h/Ax 840 and S.h/Ax 888 ) with low (L) and very low (VL) water availability. Values were averaged over two growing seasons. Vertical bars indicate standard error $(\mathrm{SE})(\mathrm{n}=5)$. DAE: days after emergence. 

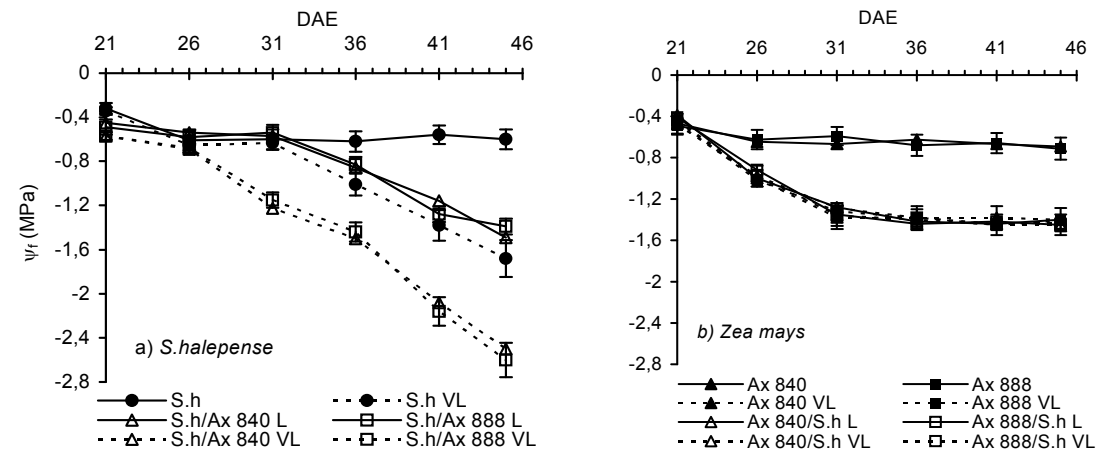

Fig. 2. Time-course of leaf water potential ( $\left.\psi_{1}, \mathrm{MPa}\right)$ for: a) Sorghum halepense monocultures at field capacity (S.h) and with very low water availability (S.h VL), and Sorghum halepense in competition with Zea mays (S.h/Ax 840 and S.h/Ax 888) with low (L) and very low (VL) water availability; b) Zea mays monocultures at field capacity (Ax 840 and Ax 888) and with very low water availability (Ax $840 \mathrm{VL}, \mathrm{Ax} 888 \mathrm{VL}$ ), and Zea mays in competition with Sorghum halepense (Ax 840/S.h and Ax 888/S.h) with low (L) and very (VL) water availability. Values were averaged over two growing seasons. Vertical bars indicate standard error $(n=5)$. DAE: days after emergence.

\section{Relative water content}

Until the 15th day after the beginning of the water availability treatments, the RWC of Sorghum halepense did not differ significantly either in monoculture or in competition with maize in the $\mathrm{L}$ treatment (Fig. 3a). The VL treatment produced a larger reduction $(p<0.01)$ in RWC in competition from the twelfth day after the start of the testing period than that observed for either competition or monoculture in the $\mathrm{L}$ treatment. By the end of the study period, the reduction in RWC was $19.5 \%$, $12.8 \%$ and $30.8 \%$ in the monoculture, $\mathrm{L}$ and VL treatments, respectively, compared to the well-watered control.
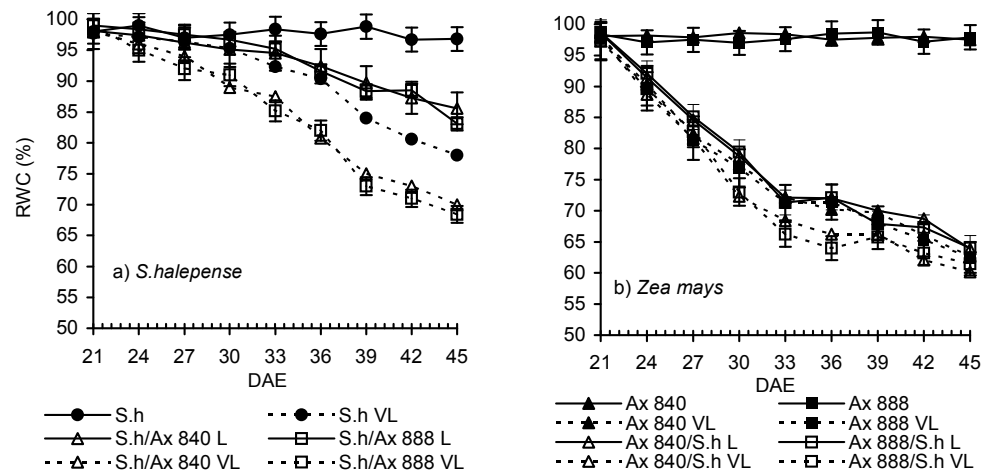

Fig. 3. Time-course of relative water content (RWC, \%) for: a) Sorghum halepense monocultures at field capacity (S.h) and with very low water availability (S.h VL), and Sorghum halepense in competition with Zea mays (S.h/Ax 840 and S.h/Ax 888) with low (L) and very low (VL) water availability; b) Zea mays monocultures at field capacity (Ax 840 and Ax 888) and with very low water availability (Ax 840 VL, Ax 888 VL), and Zea mays in competition with Sorghum halepense (Ax 840/S.h and Ax 888/S.h) with low (L) and very low (VL) water availability. Values were averaged over two growing seasons. Vertical bars indicate standard error $(\mathrm{n}=5)$. DAE: days after emergence. 
In Zea mays RWC decreased with a similar time-course in all the water deficit treatments, with or without competition, with a $15 \%$ reduction after one week and 29.3\% after two weeks (averaged over all the treatments compared with the control). At the end of the experiment, the average decrease in RWC for Zea mays hybrids was 36\% (Fig. 3b).

\section{Photosynthetic rate}

The photosynthetic rate of Sorghum halepense decreased under water deficit, with or without competition. In the VL treatment the decrease in photosynthesis was detected as early as nine days after the beginning of the treatment in monoculture and in competition with the Ax 840 hybrid, and after 15 days in competition with the Ax 888 hybrid (Fig. 4a). The L treatment had a similar effect in the Sorghum halepense monoculture and in competition with the Ax 840 hybrid, with no significant differences at any of the sampling times. In competition with maize the photosynthetic rate of Sorghum halepense in the VL treatment differed $(p<0.05)$ early from the control treatment, while in the L treatment a significant decrease in photosynthesis was not found until the second week of the testing period.

In Zea mays, both water availability levels caused a smaller decrease in the photosynthetic rate of both hybrids in monoculture than that observed under competition with Sorghum halepense (Fig. 4b). In the latter this effect was observed after a week of treatment, while in the monoculture it was observed 9 days after the beginning of the testing period. Moreover, in both treatments, the decline was particularly marked towards the end of the water deficit period. Competition in the VL treatment caused a very early decline in the photosynthetic rate, detectable on the third day after withdrawing watering. Towards the end of the 14-day deficit period there were no differences between either the treatments or the Zea mays hybrids. The average decrease in the photosynthetic rate in all the water deficit treatments was $92.6 \%(\mathrm{p}<0.01)$ compared to the irrigated monoculture.
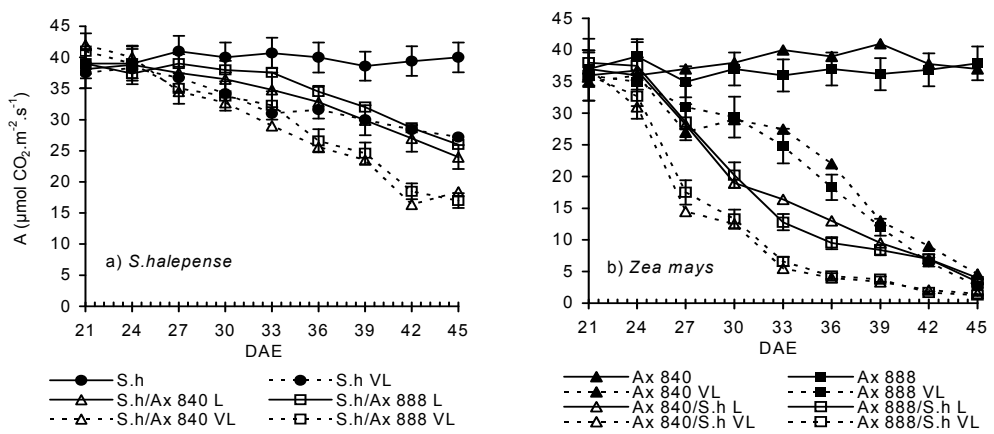

Fig. 4. Time-course of photosynthetic rate $\left(\mathrm{A}, \mu \mathrm{mol} \mathrm{m} \mathrm{m}^{-2} \mathrm{~s}^{-1}\right.$ for: a) Sorghum halepense monocultures at field capacity (S.h) and with very low water availability (S.h VL), and Sorghum halepense in competition with Zea mays (S.h/Ax 840 and S.h/Ax 888) with low (L) and very low (VL) water availability; b) Zea mays monocultures at field capacity (Ax 840 and Ax 888) and with very low water availability (Ax 840 VL, Ax 888 VL), and Zea mays in competition with Sorghum halepense (Ax 840/S.h and Ax 888/S.h) with low (L) and very low (VL) water availability. Values were averaged over two growing seasons. Vertical bars indicate standard error $(n=5)$. DAE: days after emergence. 
Stomatal conductance to water vapour $\left(G_{s}\right)$ and transpiration rate $(E)$

In Sorghum halepense grown in competition $G_{s}$ showed a significant decrease $(p<0.05) 3$ days after the beginning of the VL treatment (Fig. 5a). In the monoculture this reduction became significant $(\mathrm{p}<0.05) 6$ days after the beginning of the L treatment. $G_{s}$ continued declining in all the water deficit treatments until the end of the experiment. The transpiration rate followed a similar trend to that recorded for $G_{s}$.

In Zea mays, $G_{s}$ decreased in all the water deficit treatments. Competition combined with the VL treatment produced a highly significant reduction $(\mathrm{p}<0.01)$ in $G_{s}$ in both hybrids 3 days after treatment began (Fig. 5b). There were no significant differences between the hybrids, and $G_{s}$ decreased faster under competition in the VL treatment than in the L treatment.

Competition with Sorghum halepense produced a greater decrease $(\mathrm{p}<0.05)$ in $E$ in both hybrids than in the monoculture during the first two weeks of the $\mathrm{L}$ treatment. Water deficit caused a final average reduction of $86 \%$ in monoculture compared with the watered control, while in the case of competition the decrease was $95 \%$ and $98 \%$ (averaged over the hybrids) in the $\mathrm{L}$ and VL treatments, respectively (Fig. 6).

\section{Instantaneous water use efficiency (IWUE)}

An increase in the IWUE of Sorghum halepense was recorded when the weed competed with the Ax 840 hybrid, towards the end of the testing period (Fig. 7a). Water deficit produced a significant increase in the IWUE of the Sorghum halepense monoculture 18 days after the beginning of the testing period. The IWUE of Sorghum halepense significantly $(p<0.05)$ increased 6 to 15 days after the beginning of the VL treatment in competition with the Ax 840 hybrid.
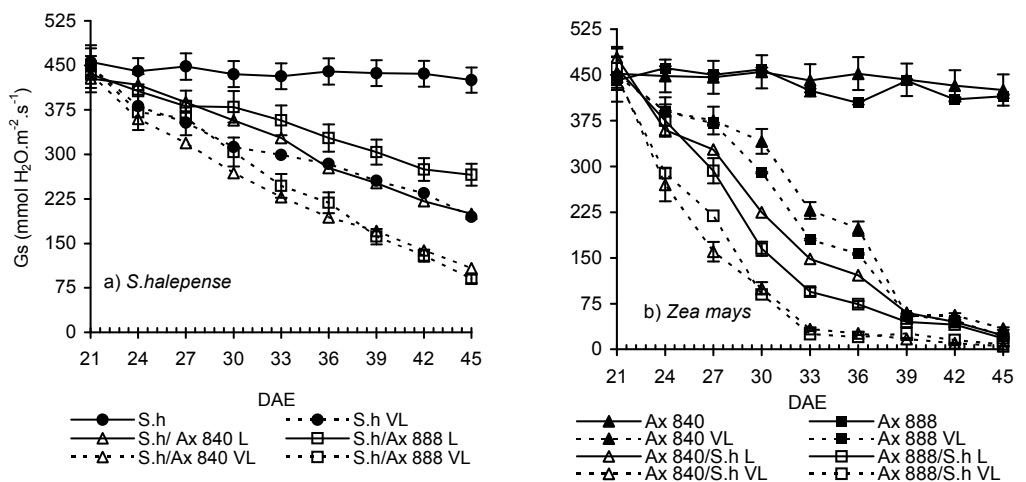

Fig. 5. Time-course of stomatal conductance to water vapour $\left(\mathrm{G}_{\mathrm{s}}, \mathrm{mmol} \mathrm{H}_{2} \mathrm{O} \mathrm{m} \mathrm{m}^{-2} \mathrm{~s}^{-1}\right)$ for: a) Sorghum halepense monocultures at field capacity (S.h) and with very low water availability (S.h VL), and Sorghum halepense in competition with Zea mays (S.h/Ax 840 and S.h/Ax 888) with low (L) and very low (VL) water availability; b) Zea mays monocultures at field capacity (Ax 840 and Ax 888) and with very low water availability (Ax 840 VL, Ax 888 VL), and Zea mays in competition with Sorghum halepense (Ax 840/S.h and Ax 888/S.h) with low (L) and very low (VL) water availability. Values were averaged over two growing seasons. Vertical bars indicate standard error $(n=5)$. DAE: days after emergence. 

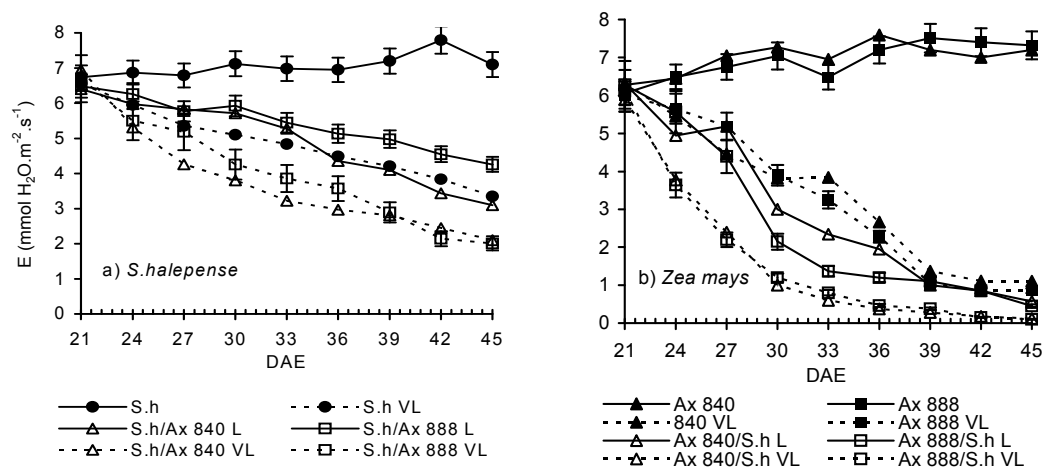

Fig. 6. Time-course of transpiration rate $\left(\mathrm{E}, \mathrm{mmol} \mathrm{H}_{2} \mathrm{O} \mathrm{m} \mathrm{m}^{-2} \mathrm{~s}^{-1}\right)$ for: a) Sorghum halepense monocultures at field capacity (S.h) and with very low water availability (S.h VL), and Sorghum halepense in competition with Zea mays (S.h/Ax 840 and S.h/Ax 888) with low (L) and very low (VL) water availability; b) Zea mays monocultures at field capacity (Ax 840 and Ax 888) and very low water availability (Ax 840 VL, Ax 888 VL), and Zea mays in competition with Sorghum halepense (Ax 840/S.h and Ax 888/S.h) with low (L) and very low (VL) water availability. Values were averaged over

two growing seasons. Vertical bars indicate standard error $(n=5)$. DAE: days after emergence.

The fluctuation in the IWUE in Zea mays was greater $(\mathrm{p}<0.05)$ than that recorded for Sorghum halepense (Fig. 7b). Weed competition produced a significant increase in the IWUE of Ax 888 nine days after the beginning of the $\mathrm{L}$ treatment, while significant differences were detected in Ax 840 after 15 to 18 days. There was a significant increase $(p<0.05)$ in the IWUE of the monocultures compared with the control 15 to 21 days after the beginning of the $\mathrm{L}$ treatment, with no differences between the hybrids. Ax 888 registered the highest IWUE in competition 4 days after the beginning of the VL treatment, while significant increases $(\mathrm{p}<0.05)$ were recorded for Ax 840 after 9 days. No significant differences were observed between the hybrids at any sampling date in competition at the very low water level (Table 1).
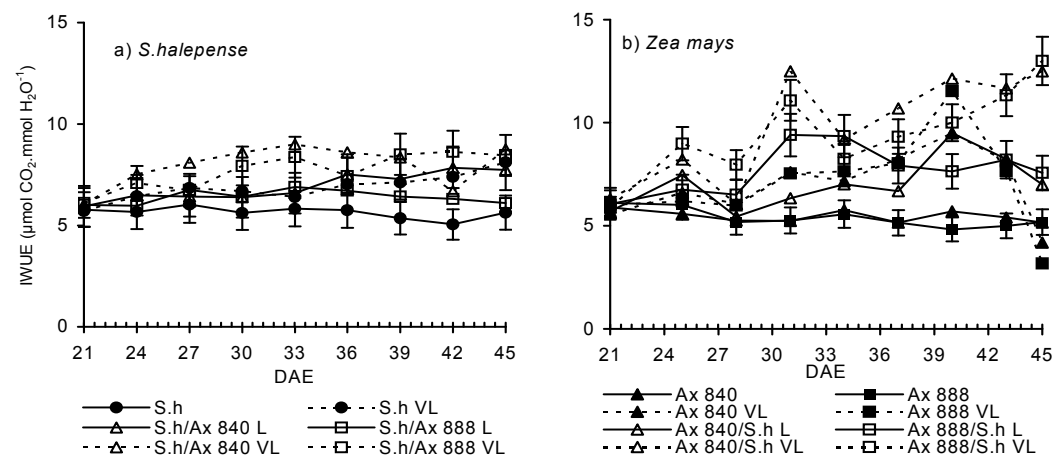

Fig. 7. Time-course of instantaneous water use efficiency (IWUE, $\mu \mathrm{mol} \mathrm{CO}_{2} \mathrm{mmol} \mathrm{H}_{2} \mathrm{O}^{-1}$ ) for: a) Sorghum halepense monocultures at field capacity (S.h) and with very low water availability (S.h VL), and Sorghum halepense in competition with Zea mays (S.h/Ax 840 and S.h/Ax 888) with low (L) and very low (VL) water availability; b) Zea mays monocultures at field capacity (Ax 840 and Ax 888) and very low water availability (Ax $840 \mathrm{VL}, \mathrm{Ax} 888 \mathrm{VL}$ ), and Zea mays in competition with Sorghum halepense (Ax 840/S.h and Ax 888/S.h) with low (L) and very low (VL) water availability. Values were averaged over two growing seasons. Vertical bars indicate standard error $(n=5)$. DAE: days after emergence. 
Table 1

Effects of time, genotype (S. halepense, Z. mays Ax 888 and Ax 840), competition and water availability on soil water potential $\left(\psi_{\mathrm{s}}\right)$, leaf water potential $\left(\psi_{1}\right)$, relative water content $(\mathrm{RWC})$, photosynthetic rate $(A)$, stomatal conductance to water vapour $\left(\mathrm{G}_{\mathrm{s}}\right)$, transpiration rate $(\mathrm{E})$ and instantaneous water use efficiency (IWUE) in terms of $p$-values (NS $=$ no significant effect at $p>0.05$ )

\begin{tabular}{lccccccc}
\hline \multicolumn{1}{c}{ Source of variation } & $\psi_{\mathrm{s}}$ & $\psi_{1}$ & $\mathrm{RWC}$ & $\mathrm{A}$ & $\mathrm{G}_{\mathrm{s}}$ & $\mathrm{E}$ & IWUE \\
\hline Time $(\mathrm{Ti})$ & 0.029 & 0.017 & 0.024 & 0.018 & 0.014 & 0.021 & 0.05 \\
Genotype $(\mathrm{Ge})$ & 0.015 & 0.000 & 0.011 & 0.000 & 0.000 & 0.001 & 0.033 \\
Competition $(\mathrm{Co})$ & 0.009 & 0.000 & 0.001 & 0.000 & 0.009 & 0.000 & 0.029 \\
Water availability $(\mathrm{Wa})$ & 0.010 & 0.000 & 0.015 & 0.000 & 0.000 & 0.012 & 0.031 \\
$\mathrm{Ti} \times \mathrm{Ge}$ & 0.019 & 0.024 & 0.04 & 0.039 & 0.049 & 0.05 & 0.047 \\
$\mathrm{Ti} \times \mathrm{Co}$ & 0.003 & 0.000 & 0.041 & 0.026 & 0.041 & 0.033 & $\mathrm{NS}$ \\
$\mathrm{Ti} \times \mathrm{Wa}$ & 0.012 & 0.000 & 0.039 & 0.020 & 0.036 & 0.042 & $\mathrm{NS}$ \\
$\mathrm{Ge} \times \mathrm{Co}$ & 0.009 & 0.000 & 0.022 & 0.001 & 0.011 & 0.019 & 0.045 \\
$\mathrm{Ge} \times \mathrm{Wa}$ & 0.007 & 0.000 & 0.031 & 0.029 & 0.030 & 0.028 & 0.05 \\
$\mathrm{Ge} \times \mathrm{Co} \times \mathrm{Wa}$ & 0.018 & 0.011 & 0.05 & 0.047 & 0.05 & 0.046 & $\mathrm{NS}$ \\
\hline
\end{tabular}

\section{Resource complementarity}

In both years, RYT values were not significantly different from 1.0 for either competition treatment, except for the first evaluation (4 days) in competition in the L treatment, where a RYT higher than $1.0(\mathrm{p}<0.05)$ was observed, confirming the absence of resource complementarity and the occurrence of full competition between Sorghum halepense and maize (Table 2).

\section{Competitive ability}

After one week in competition with low water availability, Sorghum halepense showed higher aggressivity than either Zea mays hybrid (Fig. 8). Nine days after the beginning of the L treatment Sorghum halepense was more aggressive in competition with Ax 888. This difference in aggressivity persisted until the eighteenth day. The aggressivity of Sorghum halepense in competition was even higher at a very low water level than in the L treatment, with no difference in its aggressivity towards either of the maize hybrids. This greater weed aggressivity occurred as early as the third day after the beginning of the test period.

\section{Discussion}

\section{Resource complementarity}

No resource complementarity was seen between the two species at any of the competition levels tested. The RYT values were similar to those found in other studies on competition for soil resources (Semere and Froud-Williams, 2001; Acciaresi et al., 2003; Acciaresi and Guiamet, 2010). It should be noted that even in competition at a low water level (with $\psi_{\mathrm{s}}$ ranging from $-0.04 \mathrm{MPa}$ to $-0.2 /-0.35 \mathrm{MPa}$ with a measurement interval of three days), substantial competition was observed between the two species during the critical period of competition for Zea mays. 
Table 2

Complementarity of resources (relative yield total, RYT) for Sorghum halepense in competition with Zea mays (S.h/Ax840 and S.h/Ax888) in the case of low ( $75 \% \mathrm{FC} ; \mathrm{L})$ and very low water availability (VL) at 4, 7,11,16, 20 and 24 days from the beginning of the competition treatments. LSD: Least significant difference (Tukey, $\mathrm{p}<0.05)(\mathrm{n}=5)$

\begin{tabular}{cccccccccccccc}
\hline & \multicolumn{1}{c}{ 2003-2004 } \\
\cline { 2 - 14 } RYT & \multicolumn{1}{c}{ Days of competition } \\
\cline { 2 - 15 } & 4 & 7 & 11 & 16 & 20 & 24 & 4 & 7 & 11 & 16 & 20 & 24 \\
\hline S.h/Ax840 (L) & 1.11 & 1.05 & 1.06 & 1.06 & 1.05 & 1.04 & 1.12 & 1.06 & 1.06 & 1.05 & 1.04 & 1.04 \\
S.h/Ax888 (L) & 1.12 & 1.07 & 1.05 & 1.06 & 1.08 & 1.02 & 1.11 & 1.05 & 1.07 & 1.05 & 1.05 & 1.03 \\
S.h/Ax 840 (VL) & 1.10 & 1.00 & 1.02 & 1.01 & 1.00 & 0.99 & 1.08 & 1.05 & 1.03 & 1.02 & 1.00 & 1.01 \\
S.h/Ax 888 (VL) & 1.08 & 1.04 & 1.04 & 1.03 & 0.99 & 1.00 & 1.07 & 1.05 & 1.04 & 0.99 & 1.00 & 1.01 \\
LSD & 0.10 & 0.08 & 0.07 & 0.07 & 0.10 & 0.09 & 0.09 & 0.07 & 0.08 & 0.06 & 0.06 & 0.05 \\
\hline
\end{tabular}

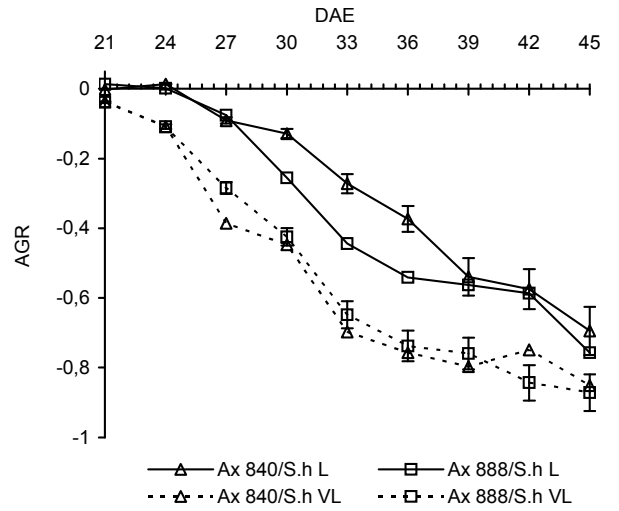

Fig. 8. Competitive ability (aggressivity, AGR) of Zea mays in competition with Sorghum halepense (Ax 840/S.h and Ax 888/S.h) grown at low (L) and very low (VL) water availability from 21 days after emergence (DAE). Values were averaged over two growing seasons. Vertical bars indicate standard error $(\mathrm{SE})(\mathrm{n}=5)$.

Soil water potential $\left(\psi_{s}\right)$, leaf water potential $\left(\psi_{\nu}\right)$ and relative water content $(R W C)$

$\psi_{\mathrm{s}}$ decreased more markedly in competition in the VL treatment than in the monoculture or in competition in the L treatment, though fluctuations in $\psi_{\mathrm{s}}$ were observed. Under water deficit, a monoculture of Sorghum halepense caused a larger decrease in $\psi_{\mathrm{s}}$ than either Zea mays hybrid, showing a higher capacity for water extraction under such conditions. Furthermore, the lower $\psi_{1}$ and higher transpiration rates of Sorghum halepense growing in competition with maize suggest that most of the reduction in $\psi_{\mathrm{s}}$ in these conditions was caused by water absorption by Sorghum halepense. This argument can be extended to competition under very low water availability, where Sorghum halepense maintained higher E values than either maize hybrid. Davis et al. (1965) stated that soil-water extraction profiles in different weed species are 
closely related to the amount of water extracted per plant, and that species adapted to low soil-water conditions reach the highest rates of water extraction when competing for water under water deficiency conditions.

Compared with either maize hybrid, there was a greater decrease in $\psi_{1}$ in Sorghum halepense in the VL treatment, whereas RWC, stomatal conductance and transpiration rate decreased relatively less. Maintaining relatively high RWC at very low $\psi_{1}$ could be related to a decrease in $\psi_{\text {os }}$ (osmotic potential) and consequently to the maintenance of $\psi_{\mathrm{t}}$ (turgor potential) in the leaves of the weed. This could be caused by the accumulation of osmolytes and/or interaction with proteins (Smirnoff and Cumbes, 1989), which would contribute to osmoprotection (Rhodes and Hanson, 1993) in Sorghum halepense under very low water availability conditions.

The behaviour of $\psi_{1}$ and RWC in Sorghum halepense agrees with data reported by Stuart et al. (1985). The rapid decrease in $\psi_{\mathrm{s}}$ in the competition treatments could have been caused by the better osmotic adjustment of Sorghum halepense compared to the maize hybrids. This would have allowed Sorghum halepense to maintain turgor and root growth (Acciaresi and Guiamet, 2010), favouring water uptake at decreasing levels of $\psi_{\mathrm{s}}$.

In the Zea mays hybrids, RWC decreased during the first week of competition and then levelled off at close to $70 \%$, with a $\psi_{1}$ of $-1.0 \mathrm{MPa}$. Even though the $\psi_{\mathrm{s}}$ values recovered to field capacity every three days in the $\mathrm{L}$ treatment, the RWC and $\psi_{1}$ of maize did not recover. The marked reduction in $\psi_{\mathrm{s}}$ could have interfered with the ability of maize to maintain osmotic adjustment and gas exchange. It should be noted that the $\psi_{1}$ of maize hybrids did not increase after each irrigation, when the values of $\psi_{\mathrm{s}}$ recovered to levels close to field capacity, suggesting that intense water absorption by the weed prevented the maize plants from recovering their water status.

\section{Gas exchange}

Changes in the transpiration rate at the two levels of competition revealed the ability of each species to capture the resources for which they competed. Thus, Sorghum halepense was more aggressive in capturing water throughout the competition period than either maize hybrid. Acciaresi and Guiamet (2010) found that, when growing under competition for water with Zea mays, S. halepense can maintain relative growth rate due to the greater density and length of the very fine roots $(<240 \mu \mathrm{m})$, and that $S$. halepense is more aggressive than maize in the vegetative stages.

As the competition period advanced, stomatal conductance decreased before the decline in the photosynthetic rate. This is consistent with studies by Chaves (1991) and Cornic (2000), who found that the inhibition of photosynthesis under moderate water deficit conditions is basically caused by a restriction in $\mathrm{CO}_{2}$ diffusion. However, Tassara et al. (1999) and Lawlor (2002) 
stated that the photosynthetic rate decreases as RWC declines, initially due to a decline in stomatal conductance and then due to metabolic (not stomatal) causes, basically linked to a reduction in ribulose 1,5 bisphosphate synthesis (Lawlor, 2002). However, Flexas et al. (1998) and Maroco et al. (2002) reported that under prolonged water deficit conditions (from days to weeks) an initial reduction in the photosynthetic rate, caused by a decline in stomatal conductance, might be followed by a new adjustment to balance photosynthetic activity with the intercellular concentration of $\mathrm{CO}_{2}$. Thus, it is possible that in Sorghum halepense the reduction in the photosynthetic rate may have been caused basically by stomatal limitations, while the inhibition of the photosynthetic rate in maize might be due to both stomatal and non-stomatal limitations.

Sorghum halepense did not show a differential water use efficiency response under water deficit and competition levels, due to the maintenance of the water status in the leaves. Greater water use efficiency was observed in both hybrids as drought stress and competition became more pronounced. In Sorghum halepense the modification of the root structure under drought conditions (Acciaresi and Guiamet, 2010) and the relative maintenance of the transpiration rate might explain the maintenance of IWUE.

The gas exchange behaviour of maize hybrids is a typical example of a conservative strategy to save soil water, with early stomatal closure (Ray et al., 1997). According to Lorens (1987a), Ray and Sinclair (1997) and Ray et al. (1997) a deficit period like that tested in this work would favour genotypes with early stomatal closure, which would lead to water conservation and survival during the deficiency period. In response to soil-water deficit, Zea mays maintained leaf water potential while reducing stomatal conductance, thereby negatively influencing leaf gas exchange and behaving as a typical isohydric species (Lambers et al., 1998). Thus, maize hybrids with a "water-saver" strategy during the critical period of competition $\left(\mathrm{V}_{4}-\mathrm{V}_{7}\right)$ could offer weeds a competitive advantage if the latter follow a "water-waster" strategy during the competition period (Patterson, 1995). Under water availability limitations, Sorghum halepense responded like an anisohydric species, slowing down the decrease in stomatal conductance at the expense of $\psi_{1}$ potential. The greater competitive ability observed in Sorghum halepense is in agreement with that noted by Taiz and Zeiger (2010) and Vamerali et al. (2003), who reported that once the appropriate water levels were recovered, active gas exchange in periods of fluctuating water availability allowed higher growth rates and the maintenance of productivity in anisohydric species. Thus, an active gas exchange during water deficit, like that of Sorghum halepense, could lead to greater aggressivity, negatively affecting the productivity of the crop with which it competes. Radosevich and Roush (1990) and Radosevich et al. (1997) concluded that the ability of weeds to rapidly reduce soil-water content and to maintain growth under these conditions was an appropriate mechanism in situations of water competition. 
The maintenance of gas exchange at low values of $\psi_{\mathrm{s}}$ and the stomatal behaviour shown by Sorghum halepense appear to be general responses of certain "water-waster" weeds under competition conditions (Patterson, 1995). Various studies on competition for water have determined that the stomata of species such as Sida spinosa and Xanthium pensylvanicum show a gradual response to the effect of competition with Glycine max (Geddes et al., 1979; Scott and Geddes, 1979; Patterson and Flint, 1983). These authors reported that soybeans saved water in the case of water competition, while the weeds showed an intense use of water. Thus, while the crop tended to optimize the use of water through stomatal closure, the weeds continued to absorb water at the expense of crop growth. In the present study, Sorghum halepense absorbed water continuously during the water deficit period, revealing greater aggressivity than either of the maize hybrids. This maintenance of aggressivity by Sorghum halepense during competition is consistent with the findings of Wiese and Vandiver (1970), who determined that species from sub-humid or semi-arid regions are more competitive than those from humid regions during water competition due to their ability to transpire under conditions where species from humid zones cannot do so. In the present study, Sorghum halepense had greater aggressivity when competing for water with Zea mays hybrids, which had conservative "water" behaviour. The results showed that soil-water fluctuations during the vegetative cycle of Zea mays could lead to an intensive competitive process dominated by Sorghum halepense.

\section{Conclusions}

Sorghum halepense absorbed water continually during water deficit, irrepective of which Zea mays hybrid it was competing with. A greater decrease in leaf water potential was observed in Sorghum halepense than in either hybrid of Zea mays, with a relative maintenance of leaf turgor in the weed. This relative maintenance of turgor (RWC) in Sorghum halepense may allow the maintenance of active gas exchange, thereby achieving greater aggressivity during competition for water.

The Zea mays hybrids tested showed a conservative soil-water strategy at both levels of competition. This behaviour favoured Sorghum halepense, which continued to consume water under deficit conditions. The maintenance of gas exchange by Sorghum halepense gave it better competitive ability at various levels of soil water competition. 


\section{References}

Acciaresi, H. A., Chidichimo, H. O., Sarandón, S. J. (2003): Shoot and root competition in a Lolium multiflorum-wheat association. Biol. Agric. Hortic., 21, 15-33.

Acciaresi, H. A., Guiamet, J. J. (2010): Below- and above-ground growth and biomass allocation in Zea mays and Sorghum halepense in response to soil water competition. Weed Res., 50, 481-492.

Bates, T. R., Lynch J. P. (2001): Root hairs confer a competitive advantage under low phosphorus availability. Plant Soil, 236, 243-250.

Bohnert, H. J., Bressan, R. A. (2001): Abiotic stresses, plant reactions, and approaches towards improving stress tolerance. In: Nosberger, J., Geiger, H. H., Struik, P. C. (eds.), Crop Science: Progress and Prospects. CABI Publishing, Wallingford, pp. 81-100.

Caldwell, M. M., Manwaring, J. H., Durham, S. (1996): Species interactions at the level of fine roots in the field: influence of soil nutrient heterogeneity and plant size. Oecologia, 106, 440-447.

Chaves, M. M. (1991): Effects of water deficits on carbon assimilation. J. Exp. Bot., 42, 1-16.

Chaves, M. M., Pereira, J. S., Maroco, J., Rodrigues, M. L., Ricardo, C. P., Osório, M. L., Carvalho, I., Faria, T., Pinheiro, C., (2002): How plants cope with water stress in the field. Photosynthesis and growth. Ann. Bot., 89, 907-916.

Cornic, G. (2000): Drought stress inhibits photosynthesis by decreasing stomatal aperture not by affecting ATP synthesis. Trends Plant Sci., 5, 187-188.

Cornic, G., Fresneau, C. (2002): Photosynthetic carbon reduction and carbon oxidation cycles are the main electron sinks for Photosystem II activity during a mild drought. Ann. BotLondon, 89, 887-894.

Davis, R. G., Wiese, A. F., Pafford, J. L. (1965): Root moisture extraction profiles of various weeds. Weeds, 13, 98-100.

de Witt, C. T., Van Den Berg, J. P. (1965): Competition between herbage plants. Neth. J. Agric. Sci., 13, 212-221.

Dudley, S. A. (1996): Differing selection on plant physiological traits in response to environmental water availability: a test of adaptive hypotheses. Evolution, 50, 92-102.

Flexas, J., Escalona, J. M., Medrano, H. (1998): Down-regulation of photosynthesis by drought under field conditions in grapevine leaves. Aust. J. Plant Physiol., 25, 893-900.

Geddes, R. D., Scott, H. D., Oliver, L. R. (1979): Growth and water use by common cocklebur (Xanthium pensylvanicum) and soybeans (Glycine max) under field conditions. Weed Sci., 27, 206-212.

Ghosheh, H. Z., Holshouser, D. L., Chandler, J. M. (1996): The critical periods of johnsongrass (Sorghum halepense) control in field corn (Zea mays). Weed Sci., 44, 944-947.

Hsiao, T. C., Xu, L. K. (2000): Sensitivity of growth of roots versus leaves to water stress: biophysical analysis and relation to water transport. J. Exp. Bot., 51, 1595-1616.

Jones, M. M., Turner, T. C. (1978): Osmotic adjustment in leaves of sorghum in response to water deficits. Plant Physiol., 61, 122-126.

Kalapos T., van den Boogaard, R., Lambers, H. (1996): Effect of soil drying on growth, biomass allocation and leaf gas exchange of two annual grass species. Plant Soil, 185, 137-149.

Lambers, H., Chapin, F., Pons, T. (1998): Growth and allocation. In: Lambers, H. (ed.), Plant Physiological Ecology. Springer-Verlag, New York, pp. 299-351.

Lawlor, D. W. (2002): Limitation to photosynthesis in water-stressed leaves: stomata vs. metabolism and the role of ATP. Ann. Bot-London, 89, 871-885.

Leguizamón, E. S., Yanniccari, M. E., Guiamet, J. J., Acciaresi, H. A. (2011): Growth, gas exchange and competitive ability of Sorghum halepense populations under different soil water availability. Can. J. Plant Sci., 91, 1011-1025.

Lorens, G. F., Bennett, J. M., Loggale, L. B. (1987a): Differences in drought resistance between two corn hybrids. I: Water relations and root length density. Agron. J., 79, 802-807.

Lorens, G. F., Bennett, J. M., Loggale, L. B. (1987b): Differences in drought resistance between two corn hybrids. II: Component analysis and growth rates. Agron. J., 79, 808-813. 
Maroco, J. P., Rodrigues, M. L., Lopes, C., Chaves, M. M. (2002): Limitations to leaf photosynthesis in grapevine under drought - metabolic and modeling approaches. Funct. Plant Biol., 29, 1-9.

Patterson, D. T. (1995): Effects of environmental stress on weed/crop interactions. Weed Sci., 43, $483-490$.

Patterson, D. T., Flint, E. P. (1983): Comparative water relations, photosynthesis and growth of soybean (Glycine max) and seven associated weeds. Weed Sci., 31, 318-323.

Poorter, H., Lewis, C. (1986): Testing differences in relative growth rate: a method avoiding curve fitting and pairing. Physiol. Plant., 67, 223-226.

Radosevich, S., Holt, J., Ghersa, C. M. (1997): Other types of interference. In: Radosevich, S. R. (ed.), Weed Ecology. Implications for Management. John Wiley and Sons, New York, pp. 302-311.

Radosevich, S. R., Roush, M. L. (1990): The role of competition in agriculture. In: Grace, J. B., Tilman, D. (eds.), Perspectives on Plant Competition. Academic Press, San Diego, pp. 341-363.

Rajcan, I., Swanton, C. J. (2001): Understanding maize-weed competition: resource competition, light quality and the whole plant. Field Crops Res., 71, 139-150.

Ray, J. D., Samson, B. K., Sinclair, T. R. (1997): Vegetative growth and soil water extraction of two maize hybrids during water deficits. Field Crops Res., 52, 135-142.

Ray, J. D., Sinclair, T. R. (1997): Stomatal closure of maize hybrids in response to drying soil. Crop Sci., 37, 803-807.

Rhodes, D., Hanson, A. D. (1993): Quaternary ammonium and tertiary sulfonium compounds in higher plants. Annu. Rev. Plant Physiol. Plant Mol. Biol., 44, 357-384.

Satorre, E. H., Snaydon, R. W. (1992): A comparison of root and shoot competition between spring cereals and Avena fatua L. Weed Res., 32, 45-55.

Scott, H. D., Geddes, R. D. (1979): Plant water stress of soybean (Glycine max) and common cocklebur (Xanthium pensylvanicum): a comparison under field conditions. Weed Sci., 27, 285-289

Semere, T., Froud-Williams, R. J. (2001): The effect of pea cultivar and water stress on root and shoot competition between vegetative plants of maize and pea. J. Applied Ecol., 38, 137-145.

Smirnoff, N., Cumbes, Q. J. (1989): Hydroxyl radical scavenging activity of compatible solutes. Phytochemistry, 28, 1057-1060.

Stuart, B. L., Krieg, D. R., Abernathy, J. R. (1985): Photosynthesis and stomatal conductance responses of Johnsongrass (Sorghum halepense) to water stress. Weed Sci., 33, 635-639.

Sultan, S. E., Wilczek, A. M., Bell, D. L., Hand, G. (1998): Physiological response to complex environments in annual Polygonum species of contrasting ecological breadth. Oecologia, 115, 564-578.

Taiz, L., Zeiger, E. (2010): Plant Physiology. Sinauer Associates, Sunderland.

Tassara, H. J., Santoro, J., de Seiler, M. C., Bojanich, E., Rubione, C., Pavón, R., Satorre, E. H., Benech Arnold, R. L. (1996): Johnsongrass (Sorghum halepense) control with Imazethapyr and Haloxyfop in conventional and vertical-tilled soybean (Glycine max). Weed Sci., 44, 345-349.

Tsuji, W., Ali, M. E. K., Inanaga, S., Sugimoto, Y. (2003): Growth and gas exchange of three sorghum cultivars under drought stress. Biol. Plant., 46, 583-587.

Turner, N. C. (2001): Optimising water use. In: Nosberger, J., Geiger, H. H., Struik, P. C. (eds.), Crop Science: Progress and Prospects. CABI Publishing, Wallingford, pp. 119-135.

Vamerali, T., Saccomani, M., Bona, S., Mosca, G., Guarise, M., Ganis, A. (2003): A comparison of root characteristics in relation to nutrient and water stress in two maize hybrids. Plant Soil, 255, 157-167.

Wiese, A. F., Vandiver, C. W. (1970): Soil moisture effects on competitive ability of weeds. Weed Sci., 18, 518-519.

Corresponding author: M. Yanniccari

Phone/fax: +54 02214838168

E-mail: marcosyanniccarri@conicet.gov.ar 